\title{
Artes y medios en transe
}

\section{Resumen}

Un panorama sobre las artes visuales tecnológicas.

Expandiendo la idea de TRANS se consideran las prácticas artísticas en la combinatoria del audiovisual tecnológico en su vinculación con el arte contemporáneo. Se analiza el uso masivo de los medios del S. XX y sus vertientes de vanguardia, haciendo foco especial en el Brasil. Se considera una historia de las artes visuales y su experimentación en relación con las escenas de formación.

Palabras clave:

Artes visuales: experimentación, hibiridización, escenas de formación 


\title{
Arts and media in trance
}

\author{
JORGE LA FERLA
}

Keywords: Media arts: experimentation, hybridisation, scenes of instruction

\section{Abstract}

A status report and an overview on the history of media arts. Considering the idea of TRANS applied to the artistic practices we analyse the audiovisual in relation with contemporary art. A reflection on the use of technological media along the XX century the text focuses on the scenes of instructions and the development of avangard hybrid audiovisual practices in Brazil throughout the last decades. 


\section{Introducción a un estado de situación}

La propuesta de este VI Seminário Nacional de Pesquisa em Arte e Cultura Visual nos ofrece una buena oportunidad para replantearnos la producción, la producción artística y la formación en un área poco trabajada por la academia como es la historia de los estudios audiovisuales. El ámbito de este encuentro en la UFG Universidade Federal de Goiás en la Faculdade de Artes Visuais resultan movilizadores en relación a un debate aún pendiente sobre las escenas de instrucción vinculadas a las artes audiovisuales. La materialidad original del cine y el video nos remite a un relato sobre la imagen en movimiento que consideraba las máquinas fundacionales del aparato de base del cine, la televisión y el video, el multimedia como determinantes en su especificidad y combinatoria. Pensar el audiovisual en esta segunda década del tercer milenio presenta la paradoja de una praxis con prácticas artísticas híbridas a partir del predominio absoluto del aparato informático, que en su origen y desarrollo no fue concebido como máquina de imágenes. La creciente vinculación con el arte contemporáneo, viene desplazando la exhibición audiovisual de la sala oscura y la pantalla blanca, del monitor y el proyector hacia el cubo blanco del museo, las redes y los dispositivos móviles. Estos últimos años, el cruce de la frontera del analógico al digital conmueve a la imagen en movimiento generando especulaciones sobre el devenir del espectáculo y el consumo masivo tanto como de la producción independiente, incluidas la prácticas artísticas y la enseñanza. A poco tiempo de cumplirse el primer siglo del inicio de los estudios cinematográficos, la formación vinculada a la academia ofrece serias contradicciones teniendo en cuenta estos cambios significativos en la tecnología, la producción y el consumo 
audiovisual. Cuando en el siglo pasado fueron surgiendo la TV, el video, el multimedia, hasta cierto punto de su historia, cada medio pudo ser considerado de manera particular y diferenciada, siendo la tendencia asentar la reflexión sobre esas marcas específicas. Para el campo de los estudios de cine, ideológicamente redundó en un coto cerrado para cualquier otro medio. A partir de los años 6o esas fronteras se volvieron ambiguas a partir de la imbricación entre los diversos soportes en términos de creación interdisciplinaria y experimental. Frente a la actual disolución de los soportes tradicionales y la imposición masiva de las nuevas tecnologías retomar aquellas propuestas brinda pistas que nos permiten analizar hoy un estado general del audiovisual tecnológico.

La migración a la imagen numérica tiene antecedentes en aquellos visionarios que a lo largo de la historia definieron de manera pionera la hibridez entre los medios y tempranamente se pusieron a investigar en las posibilidad de creación asistidos por un ordenador. Las ideas y obras que en su momento aplicaron la convergencia de variedad y tecnología', son la mejor antesala conceptual para considerar este proceso actual de diálogo entre los medios y de su uniformidad digital. Recordemos la obra de Stan Vanderbeek quien le dio el título a las antológicas crónicas de Gene Youngblood reunidas en su libro Expanded Cinema uno de los primeros que sistematizó un amplio espectro de experiencias con los medios audiovisuales, que confluyeron en propuestas que surgen de la sumatoria de otras tecnologías (digitales, electrónicas, holográficas) que consideraban otras posibilidades para el cine. Los manifiestos de los años 6o de Vanderbeek, sobre Intercomunicación Cultural (Cultural Intercom) y SocialImagestics ya remitían a una praxis temprana que excedía el cine y las artes visuales tradicionales. Marshall McLuhan fue otro de los autores que propuso otro espacio de reflexión el cual concebía las relaciones híbridas entre los medios como liberadoras de potenciales creativos, partiendo de las características materiales, únicas y diferenciales de cada tecnología, como el lugar específico que definía la esencia de los mensajes. Al final de los años setenta, el cine de largometraje hacía propia estas contaminaciones, debido a irrupción de la imagen electrónica en el mercado audiovisual, continuando con aquellas expansiones que el cine experimental venía ensayando desde la década anterior en su relación con el ordenador. Antonioni, Coppola, Godard, Wenders fueron algunos de los artífices que marcan vertientes de 
cruce con el video y la televisión para el cine de ficción y no ficción. Fue el realizador brasileño Gustavo Spolidoro quien con su film, De Volta ao Cuarto 666 (2008), concluía de manera inteligente un debate abierto décadas anteriores por Wim Wenders en Room 666 (1982) en Wenders trato el tema de crisis del cine, y de sus relaciones con el video y la TV. A partir de una serie de entrevistas a directores de cine durante el festival de Cannes Wenders se cuestionaba el dudoso futuro del cine frente al advenimiento de la imagen electrónica, que ya se presentaba como una alternativa de producción audiovisual. Medio siglo después, en Porto Alegre, es Wenders quien se refiere a esa preocupación, y crisis, como saldadas pues el cine perdura en su transferencia digital ${ }^{2}$.

En varios momentos de su historia, el cine estableció una permanente serie de relaciones con los diversos medios a partir de modelos híbridos ${ }^{3}$ o transmediáticos, es decir, de interrelación, acompañamiento, fagocitación, mutación, convergencia. Diversos autores han formulado conceptos funcionales que permiten abordar el tema, proponiendo categorías que se pueden aplicar a este diálogo entre los medios ${ }^{4}$ para considerar algo que Raymond Bellour determinó en su momento como entreimágenes o como una querella de los dispositivos 5 .

\section{Del cine y su expansión}

El denominado MRI - Modo de Representación Institucional ${ }^{6}$ que funciona tempranamente como sustento de Hollywood para un modelo de cine de consenso masivo que se presentaba transparente en su dispositivo y forma. Nacimiento de una Nación ${ }^{7}$ fue una de sus piedras fundantes, como el concepto y el parámetro del espectáculo fílmico industrial. Sin embargo este film emblemático cumplirá pronto su primer siglo de existencia con el soporte fílmico ya fuera de circulación, y el homenaje será en proyecciones digitales, en sala o a través de internet. La impronta de David Griffith generó un modelo perfecto, aunque estanco, de relato aún vigente en el cine comercial. Los principios del montaje paralelo y el establecimiento de la variable del punto de vista, practicados por Griffith como esencias del recorte del espacio y el tiempo en el relato, derivarían con Sergei Eisenstein en propuestas formales y conceptuales. La inspiración inicial que ejerció la obra de Griffith iba a continuarse en proyectos más radicales, focalizados en una experimentación a ultranza enfrentada al proceso cinematográfico de producción 
basado en lo comercial a partir de formatos de espectáculo sistematizados. El cine soviético se imponía en varios frentes, impulsado desde la política del Estado que promovía el cine como un elemento fundamental de cultura y propaganda, "la más importante de la artes", según Lenin. La influencia de David W. Griffith fue de notable inspiración para el sentido y la forma del cine soviético. El montaje paralelo, la ruptura del punto de vista unívoco de la cámara en la simulación del espacio teatral a la italiana, la elipsis en el corte del guión literario y un concepto integral de puesta en escena implicaban una concepción de alto nivel de escritura, a partir de la aplicación de una estructura basada en un lenguaje propio y específico del cine. Sin embargo, recordemos que dentro de la revolución que produce el cine soviético en los años 20, Eisenstein diseña por fuera dos proyectos donde aplica ideas diferentes a las plasmadas en sus realizaciones cinematográficas y teatrales, que excedían las posibilidades del cine de ese momento. Los proyectos El Capital, basado en la obra de Marx, y La casa de vidrio, obsesionaron durante largo tiempo a Eisenstein en algo que se apartaba radicalmente de sus proyectos fílmicos de esa época. En 1926 durante su estadía en Berlín, cuando asiste al estreno de El acorazado Potemkin (1925), Eisenstein comienza a pensar un film inspirado en la utilización de vidrio en arquitectura, considerando un hábitat urbano que disponía un diálogo entre interior y exterior basado en el efecto y el concepto de la transparencia. Si bien Eisenstein ya estaba trabajando en lo que serían sus dos nuevos films, Octubre (1927-1928) y La línea general (1926-1929), Glass House y Das Capital, se convierten en una obsesión. La idea del montaje de atracciones, de Eisenstein, partía de la organización narrativa instaurada por Griffith, quien a su vez tradujo para el relato cinematográfico parámetros de la narrativa de la novela del S. XIX. A pesar de sus innovaciones, esta vanguardia del cine ruso, sin embargo, se afirmaba en el principio de la representación clásica renacentista de la realidad, basada en la óptica y su recurso a la perspectiva reafirmando el compromiso de la analogía fotográfica con lo real. El diseño del cuadro para la imagen en movimiento en profundidad de campo y en superficie seguía respetando el carácter naturalista y figurativo. Sin embargo, la sentencia de Kazimir Malevich ("Es necesario estudiar los modos de representación pictórica porque, en cualquier caso, la influencia de la pintura sobre la composición del cuadro cinematográfico y sobre la presentación de los temas de las películas sigue actuando como un efecto de cuadro de caballete" de 
"Leyes pictóricas en los problemas cinematográficos", 1929) iba a hacer mella en Eisenstein, pues cuestionaba la difícil relación entre la expresión pura abstracta y la representación de lo real que debería asumir el cine. A pesar de sus particularidades, el cine mantiene hasta el día de hoy un mismo modelo, basado en contar una historia a partir de la captura de acciones de personajes frente a cámara en una locación o un set de filmación. La construcción del espacio y la representación del tiempo, están siempre concentrados en esta única variable uniforme. En su identificación de los films de ficción como un 'super-género' del cine del siglo XX, La casa de vidrio y el El Capital basaban su trama inspirados en la propuesta narrativa del Ulyses de Joyce. "El sábado recibí el Ulyses, la Biblia del nuevo cine", escribía Eisenstein en su diario. En noviembre de 1929 se reuniría con el escritor irlandés. La representación de un espacio fragmentado, y un tiempo de ruptura, respondían anticipándose a la crítica de Malevich de la representación figurativa y la narrativa lineal. En Glass House, la estructura transparente de la escena, algo que la asemejaba a un rascacielos de vidrio, contenía numerosas historias para un determinado contexto espacial, aunque entraban en conflicto por las otras acciones simultáneas visibles gracias a la arquitectura transparente que permitía ver a través de las paredes. "La desfamiliarización del punto de vista", alegaba Eisenstein en el guión de La casa de vidrio, cuestionando la representación unívoca del espacio, planteando una serie de situaciones simultáneas, vinculadas a partir de una multiplicidad de acciones bajo la mirada del espectador y de los mismos personajes. La preproducción del proyecto, resistido incluso por el entorno ruso de Eisenstein durante su estadía en Hollywood, fue abandonada al poco tiempo. En ese momento, Einsenstein ve un diseño del proyecto de rascacielos de vidrio de Frank Lloyd Wright, para el Lower East Side de Manhattan, y lo considera una verificación formal de su proyecto. Lloyd Wright planteaba un hábitat luminoso y transparente, alejado del hierro y el hormigón de las casas, algo que equivalía para el cineasta ruso al cubo cerrado del set de filmación. La estructura de Das Kapital y de Glass House se inspiraba en la trama de la novela de Joyce, extrapolando una serie de ideas que anunciaban una ruptura radical con el cine clásico y el modo de representación instituido por el cine de vanguardia. Arquitectura y literatura inspiraron a Einsenstein abriendo una serie de posibilidades para el cine, basadas en la ruptura del tiempo lineal. Y luego, poco tiempo después, llegaría Límite. 
Figura 1

Eisenstein La casa de cristal
A mensagem de cinema, da América do Sul, daqui a vinte anos, tenho certeza, será tão nova, tão cheia de poesia e de cinema estrutural, como a que assisti hoje. Eu jamais segui um fio tão próximo ao genial como o dessa narração de câmera sul-americana $(\ldots)^{8}$.

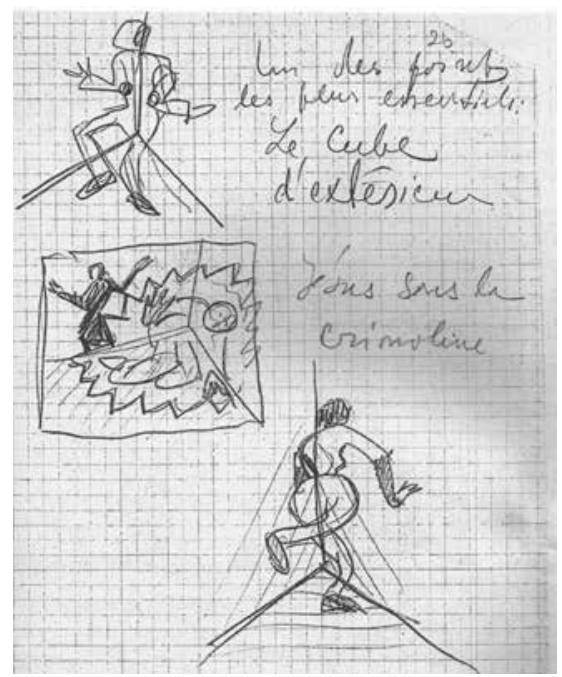

Siempre es revelador pensar el film de Peixoto considerando este momento en que fenece el soporte fotoquímico, de hecho es impactante el hecho de que podamos visionarlo en este display que ofrece YouTube, en esta transcripción on line de dudoso origen. Varias circunstancias resignifican Límite bajo el actual efecto homogeneizante del aparato digital bajo el imperio cybercultura una de las cuales es este acceso a al visionado de una película la cual no pudo ser vista durante décadas por estar extraviada o detriorada sus copias. Focalizarse en estos inicios de la historia del cine de vanguardia en nuestra región, y particularmente en Brasil, es importante por las maneras de poner en práctica un modelo de relato que se apartó del cine comercial de largometraje, y marcó el inicio de una vertiente de búsqueda formal y experimentación expresiva. Límite marcó un derrotero que se separaba del cine clásico y uniforme que se venía dando en América del Sur desde la década del 20. Julio Bressane, Leticia Parente, Glauber Rocha, Eder Santos, Lucas Bambozzi son algunos casos de autores que continuaron con esta búsqueda expresiva en el Brasil y que podemos considerar como herederos de Peixoto. Límite deslumbra y crece en el tiempo por sus opciones de puesta en escena que comentan 
sobre una manera de hacer cine en las decisiones virtuosas de recursos como la composición de cuadro y la construcción del espacio, la no linealidad entre las escenas, la eliminación de los diálogos, entre muchos otros. Límite basa su estética en el uso de la elipsis, en la metáfora, en la ambigüedad y en la negación en mostrar la obviedad de los vericuetos narrativos que dan pistas para seguir un relato clásico. Este factor de extrañamiento reclama del espectador otra mirada, la cual no está sujeta a la ilusión de la identificación con las acciones lógicas y encadenadas. Nos parece relevante revisar la historia de estos derretores de búsqueda vanguardista, pues es en estos trayectos que podemos reconstruir una tradición de experimentación, particularmente en Brasil y América Latina, cuya reformulación en estos momentos se plantea como central.

\section{Los estudios de las artes audiovisuales}

Asimismo nos parece relevante hacer referencia a la historia de los estudios audiovisuales que tiene lugar a lo largo del S.XX Recordar el nacimiento y desarrollo de los denominados Film Studies y Media Studies, nos resulta revelador. La enseñanza y la práctica de la creación con los medios audiovisuales es una tarea compleja que requiere de parámetros distintos de los que rigen en la mayoría de los establecimientos de enseñanza. Una frontera permanece latente, incidiendo de manera decisiva sobre lo que podría ser un concepto diferente de realizador luego de un siglo de uniformidad en los estudios cinematográficos. El estreno de El nacimiento de una nación ${ }^{9}$ coincide con los primeros antecedentes de estudios cinematográficos no curriculares en la Universidad de Columbia ${ }^{10}$ pocos años después nacería la primer escuela, concentrada en la actuación, en América Latina $^{11}$. Pero la gran referencia es el primer centro de enseñanza integral de cine, la GIK creada en la Unión Soviética en 1919, la cual podemos considerar sin lugar a dudas como la primera escuela de cine de la historia, concebida con un claro concepto formalista. Luego en 1935 nacía en Roma el Centro Sperimentale di Cinematografia, proyecto cultural e ideológico del gobierno de Mussolini. Pero fue en ese mismo año que Iris Barry funda The Film Library, es decir el Departamento de Cine del Museo de Arte Moderno de Nueva York, que iba a dedicarse a la conservación, difusión, investigación y enseñanza del arte del film desarrollando una amplia tarea de formación a lo largo de todo el país ${ }^{12}$ Estas iniciativas visionarias generaron un sistema de estudio en base a curriculas que se mantuvieron estancas 
por un casi todo un siglo, y mantuvieron los estudios cinematográficos en un su coto, cerrado y específico, a pesar de todos los cambios tecnológicos y de dispositivos que se fueron adosando al cine a lo largo del tiempo. Fue recién a principios de los años setenta que surge otro modelo de instrucción, el Media Study, en la Universidad de Buffalo ${ }^{13}$. Gerald $\mathrm{O}^{\prime}$ Grady revoluciona la formación audiovisual al proponer una línea de estudio compuesta por una amplia combinatoria de disciplinas que abarcaba la praxis con la fotografía, el cine clásico, la televisión, el cine experimental, el video, la radio, la televisión, la informática y las instalaciones, entre otros. Un proyecto visionario formulado hace cuatro décadas que sigue siendo una gran referencia frente a una problemática aún no resuelta en la actualidad por la mayoría de las escuelas de artes audiovisuales y carreras de cine. Un proyecto significativo en la historia de los estudios visuales interesante en relación a este fantástico proyecto del Media Lab en la Facultad de Artes Visuales de la UFG ${ }^{14}$.

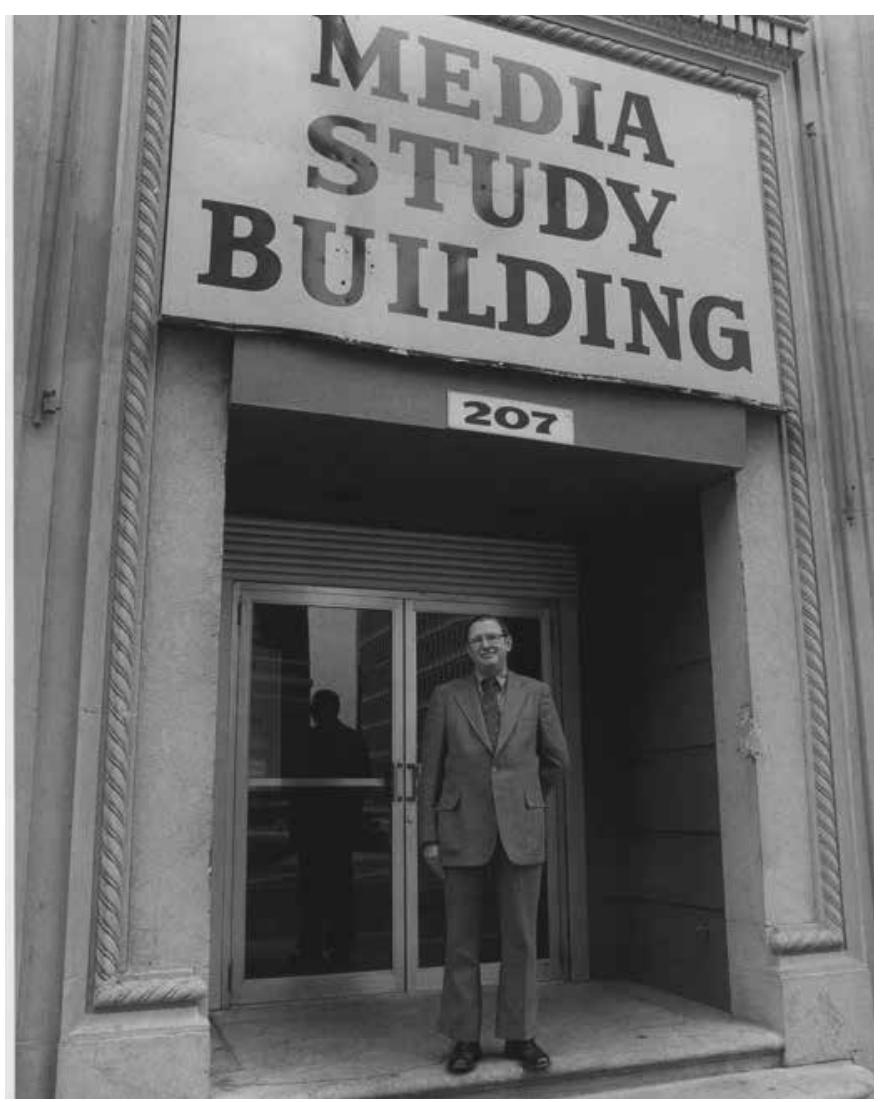


En aquel legendario departamento de Media Study de la Universidad de Buffalo, el término "estudio" definía también el concepto desde lugar físico para la faena artística. Un laboratorio, conjunción de atelier, set, oficina técnica donde confluían la fotografía, el cine, el video, la robótica, las instalaciones, la radio y la TV. Buffalo fue una de las primeras universidades que sistematizaría el estudio del cine experimental, el video arte y la televisión y los procesos artísticos de la exhibición y transmisión pensando en la confluencia de los usos masivos y las prácticas creativas con los medios. Algunos de sus instructores fueron nada menos que Hollis Frampton, Paul Sharitz, Woody Vasulka, Steina Vasulka, Peter Weibel quienes formaron parte de este departamento dirigido por Gerald O'Grady. De ahí, la reivindicación del Media Study como una propuesta de referencia para considerar en un presente en el que las artes tecnológicas suelen estar a la deriva en su escena de instrucción.

\section{Instalaciones audiovisuales}

Aquellas búsquedas experimentales de los años 60 y 70 , algunas llevadas a cabo en los mismos establecimientos académicos, fueron estableciendo otros espacios de exhibición para una variedad de proyectos pensados para ámbitos que trascendían el dispositivo de proyección monocanal y se transfirieron en parte a obras y propuestas bajo la forma de instalaciones destinadas a espacios expositivos vinculados a las galerías y los museos. Un audiovisual que nos remite a la historia de las instalaciones y que testimonia de la paulatina incorporación obras en que fotografía, el cine y el video, y las nuevas tecnologías eran concebidos para un área tridimensional practicada. Uns historia determinada por el desplazamiento de las máquinas de proyección y exhibición al cubo blanco a los espacios de arte. Primero fueron los proyectores de cine de paso reducido y $16 \mathrm{~mm}$., luego los monitores de tubos de rayos catódicos y los proyectores de video de uno y tres tubos hasta que finalmente toda el sistema de proyecciones se trasladó a información numérica a través de los data projectors, los plasmas y variados soportes de pantallas móviles. La materialidad de la exhibición de las imágenes y su dispositivo expositivo son parte del concepto del diseño tridimensional de la instalación. Las experiencia pioneras del Movie-Dome concebido por Stan Vanderbeek, construido en 1964 en Stony Point, estado de Nueva York, fue fundacional para concebir otro teatro de operaciones de participación y 
consumo audiovisual. Fue en esta cúpula cóncava que ofrecía una "pantalla de proyección infinita", el lugar donde las imágenes en movimiento se combinaban con diapositivas, gráfica, textos, animaciones y "collages electrónicos". El público podía estar sentado, acostado o moviéndose según el caso, inmerso en un panorama visual, y sonoro, que ya proponía otro tipo de exhibición, y percepción, audiovisual ${ }^{15}$. Este agenciamiento del sujeto espectador con las imágenes maquínicas fuera de la pantallas rectangulares y las butacas, retomaba la historia de los panoramas cinematográficos de feria de los inicios del cine y se iba a instalar en el espacio menos plebeyo del arte contemporáneo $^{16}$. Son recordadas las Bienales de arte de Venecia de 2005 y de San Pablo de 2010, pues marcaron una frontera conceptual cuando ofrecieron una cantidad mayoritaria de obras audiovisuales en sus espacios de exposición. Sin embargo, quedaba claro que no todas las obras de este cine de exposición podían ser consideradas como instalaciones. Muchas de estas obras eran proyecciones de los films monocanales, trasladados al espacio museístico. Salvo raras excepciones, era discutible el status de instalación de muchas de esas piezas, debido a que no había un diseño, por parte del autor, del espacio practicado con los trayectos y la relación temporal de los recorridos del espectador. En muchos casos ni siquiera el realizador había estado presente en el montaje. Por esto es que hacer referencia a las exposiciones Collages de Francia (2006) y Viajes a la utopía (2013) que tuvieron lugar en el Centro Pompidou de París ${ }^{17}$ a las cuales quería referirme como un proyecto ejemplar y aprovechando la circunstancia de su exposición actual en Río de Janeiro ${ }^{18}$. En la maqueta del proyecto que realiza artesanalmente Godard se propone la construcción de un relato ensayístico sobre la historia y ontología del cine. Múltiples proyecciones en diversos soportes, objetos, pinturas originales, libros, intervenciones tipográficas, textiles, ofrecían una compleja teoría de conjuntos sobre el cine a ser dispuestos en el espacio de una galería. El montaje de la primera versión de la exposición terminaría siendo desautorizada públicamente por Godard que se exhibiría inconclusa, debido a cuestiones de escala en el armado de las salas que no respondían a la idea original. Aquella maqueta artesanal construida por Godard con sus propias manos se convirtió en testimonio proyectual de un plan inacabado. El modelo de cartulina, acuarelas y pegamento escolar concentraba todas las combinaciones escenográficas y tecnológicas que no lograron materializarse en el montaje real. Así Godard se plantaba como artista, alejándose de la tendencia de algunos 
directores de cine que ampliaban el universo de sus películas a simples formas de su proyección trasladada al espacio museístico $^{19}$. Y si bien podemos destacar la obra de Chantal Akerman, Lucas Bambozzi, Kiko Goifman, Douglas Gordon, Peter Greenaway, Cão Guimarães, Fabián Hofman, Abbas Kiarostami, María Paz Encina, Mariana Rondón, Eder Santos, Agnès Varda, Apichatpong Weerasethakul quienes han incursionado en el largometraje y en las instalaciones, esta práctica sigue siendo una excepción para un cruce conflictivo considerando entre el cine y el video. Por su parte, recordemos que Brasil tiene una historia admirable en este campo considerando un derrotero antológico que va desde Hélio Oiticica hasta André Parente, artista y un estudioso del tema ${ }^{20}$.

\section{Trans Brasil}

Las prácticas artísticas contemporáneas han expandido la producción audiovisual hacia las redes, la performance interactiva, las instalaciones inmersivas, los dispositivos móviles y los procesos de transmisión. La imagen numérica incorpora parámetros como la programación, el diseño de interfaces, la interconectividad, que ahora se imbrican con el lenguaje cinematográfico y videográfico, en su transferencia y simulación digital. Sin embargo son pocos los autores que han incursionado en el tema. A partir de esto me interesa trazar un breve recorrido por algunos trabajos, y autores, que en estas últimas dos décadas, siempre desde Brasil, han venido generando un derrotero virtuoso en sus prácticas artísticas vinculadas a las variables tecnológicas de los últimos años. Me permito entonces la osadía, de citar una serie de ejemplos refernciales a partir de algunos realizadores brasileños que estimo han venido marcando tendencia a nivel nacional e internacional.

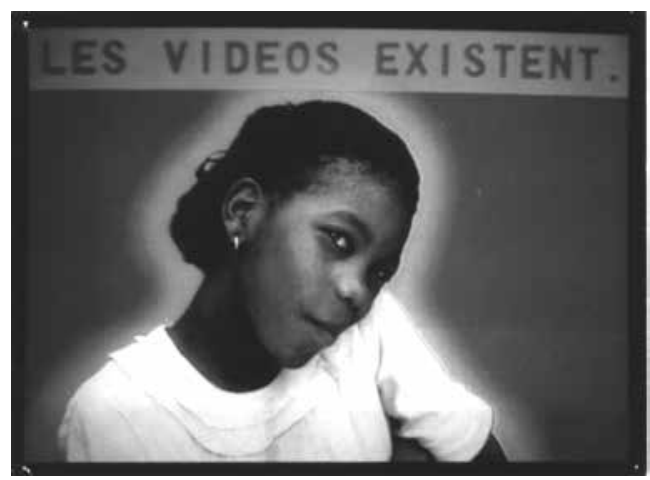


La obra de la carioca Sandra Kogut es una caso sintomático por sus diversas experiencias de creación resultado de un uso transversal en la combinatoria mediática. Durante los años 80 produjo una serie de videos en diversos formatos que constituyen una serie de lecturas sobre Brasil, y las maneras de leer la gente y el contexto urbano. La propuesta de Videocabinas son cajas negras ${ }^{21}$ se prolongó en Parabolic People (1992) donde la utilización del equipamiento digital sirve, en este sentido, para concretar otra combinatoria y otro concepto. $\mathrm{Pa}$ rabolic People $e^{22}$ configuró un un nuevo espacio de relato visual y sonoro. La múltiple combinación de imágenes en cuadro testimonió una dimensión que marcó por largo tiempo una estética en el video experimental y el uso de las instancias de navegación que ofrecen las redes a nivel comercial. Esa puesta en escena en capas tenía su correlato en la concepción del sonido, expandiendo el campo del directo referencial, proponiendo un universo sonoro de igual complejidad al de las imágenes superpuestas. Sandra Kogut se pasaría del video a la TV, y antecede con la realización de un cortometraje fílmico ${ }^{23}$, su primer largometraje de ficción ${ }^{24}$. Un modelo diverso de artista trans audiovisual que recorre todos los formatos y soportes de la imagen logrando obras que resultan de esta combinatoria entre una tecnología específica y un imaginario virtuoso.

Otro caso de referencia, es el de Eduardo Kac, desde hace muchos años en la vanguardia en el campo del arte y la tecnología quien posee una larga trayectoria de obras y proyectos de los cules quería hacer referencia y que es Time capsule ${ }^{25}$ (1997) en su momento y de manera pionera puso en escena una convergencia de medios y prácticas artísticas que van de la performance a Internet, de la TV a la fotografía. La acción performática realizada en la Casa de las Rosas de San Pablo propone una confluencia de procesos artísticos cuya especificidad y combinaoria produjo un elocuente impacto y mensaje. Kac al introducir un microchip en su pierna ponía en juego una serie de variables significativas que reformulan el género del autorretrato y el ensayo audiovisual las cuales reflexionan sobre la relación hombre/máquina y los valores de la memoria. Esta obra que combina la performance con la instalación en su combinatoria construyen otro sentido en su mediatización a través de las cámaras de TV, la documentación en video, la transmisión de datos por internet. Las fotografías de los ancestros del artista, colgadas en las paredes adyacentes de la escena de su actuación resignificaron toda la acción pues remitían a las imágenes de los ancestros del artista, rememorando y generando una per- 


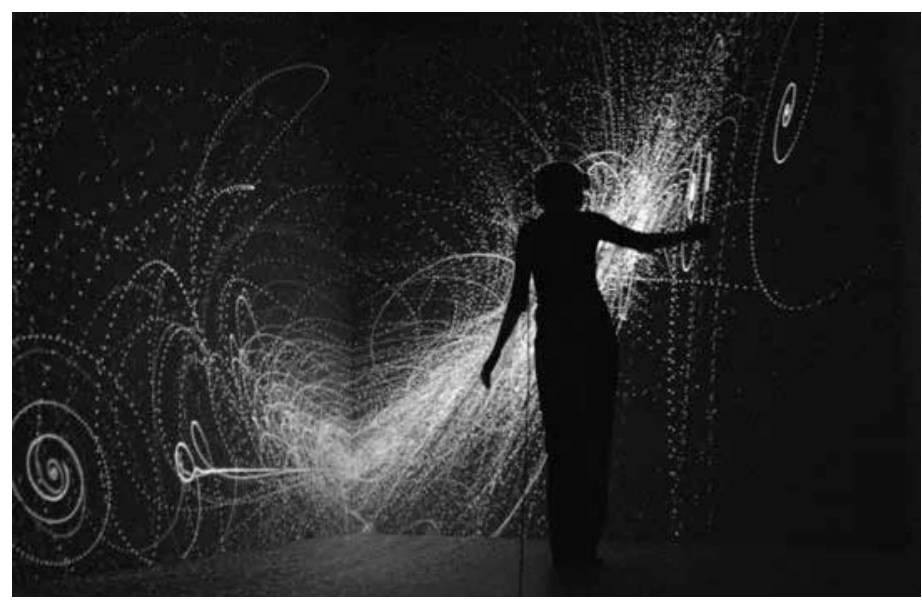

Figura 4

Rejane Cantoni y Daniela Kutschat. OP_ERA

cepción que aún sólo la fotografía logra imponer como testimonio de una memoria histórica y afectiva.

Otro referente es OP_ERA ${ }^{26}$, de las artistas brasileñas Rejane Cantoni y Daniela Kutschat, que nos remite a la ópera lírica como género, al concepto de la puesta en escena del cuerpo desde el teatro al cine, a la composición musical, a las instalaciones, a la concepción de realidades virtuales y a una práctica de cine y video expandido. Una de las versiónes del proyecto, la más trascendente según mi parecer, tuvo lugar en una caverna virtual ubicada en la USP para propuesta imersiva interactiva donde el performer es el usuario/actor quien en su recorrido hace funcionar la obra. Su cuerpo es el agente que produce el espectáculo audiovisual que su desplazamiento genera. Esta cave que convierte en pantallas el habitáculo, paredes y piso, implicó un espacio virtual donde la caja de contención es un cubo escénico virtual ${ }^{27}$. Una obra que funcionaba en base a un diseño de programación que operaba por la información de los sensores que registraban el movimiento del espectador generando espacios imaginarios no figurativos.

Lucas Bambozzi, es otro de los referentes cuya obra he venido siguiendo a lo largo del tiempo quien ha venido incursionando recientemente en el campo del multimedia, la robótica, las tecnologías móviles y las instalaciones interactivas continuando una búsqueda virtuosa que inició con el video arte y el documental de largometraje. El tiempo no recuperado (2004) en su versión de DVD ROM reformula el género del autorretrato documental para una escena digital e interactiva. Desde una base de dato que continene registros en video de diferentes momentos de su vida en que su cuerpo, su voz y su mirada, re- 
visitan un diálogo con acciones pasadas registradas en video. La manera en que Bambozzi se situarse desde el registro con la cámara y las complejas relaciones con el encuadre van dejando la impronta de enunciación cuy combinatoria es generada el programa aplicado. Esos videos que son luego transformados en archivos digitales, se configuran a través de manipulaciones algorítmicas operadas por el sistema Korsakow, programa diseñado en la Universidad de Berlín. Así es como Bambozzi plantea una fina ironía con respecto a los actos de leer, memorizar y recordar a través de los vestigios audiovisuales, sonidos e imágenes registrados con su propia cámara de video convertidos en archivos digitales y por ende, recombinados a través de la programación. El recurso a este programa es relevante pues genera motores de búsqueda que dan forma a las diversas configuraciones narrativas, que se van construyendo en el momento del consumo bajo la forma de una aparente aleatoriedad. Todo está predeterminado, pues está programado, pero se va articulando en el momento de su uso; sin interacción. Las relaciones espacio-temporales de la representación son elegidas por el usuario desde las opciones abiertas por el realizador, basadas, sin embargo, en una estructura matemática predeterminada. Podemos ver así cómo las posibilidades de puesta en escena de los laberintos de la memoria dependen de la máquina, del programa, y, en última instancia, del interactor que actualiza sus variables. Estos procesos matemáticos y tecnológicos son la cláusula a través de la cual Bambozzi ejerce su virtuosismo, construyendo una obra que impacta por proponer una lectura de sí mismo que nos sitúa, frente a una forma de escritura documental que en traslado al computador produce otras formas de relato que nos remiten a un discurso sobre los aparatos y discursos audiovisuales.

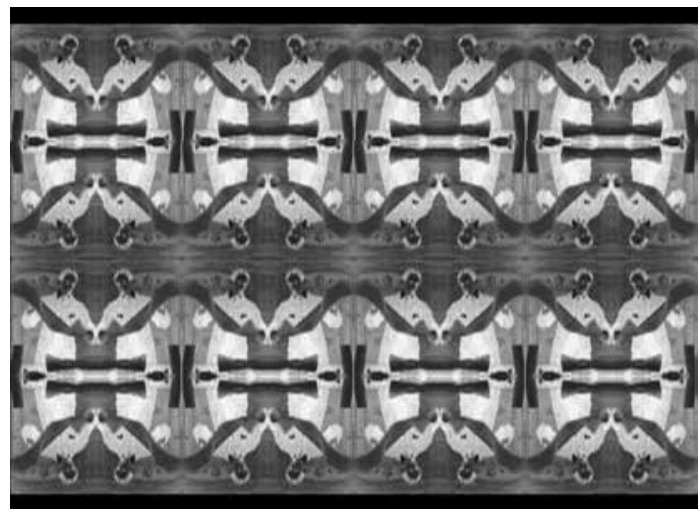


En esta línea de reformular el documental, me gustaría referirme a la obra de Carlos Adriano, otro ejemplo de trabajo, que formula un diálogo intenso sobre los medios y sus dispositivos. Sus ensayos audiovisuales reconsideran los inicios de la imagen en movimiento ${ }^{28}$. Esta(s) prehistoria(s) del cine que traza Adriano recupera archivos de registro del mutoscopio y las reconstituye en su film Santoscópio $=\mathrm{Du}$ montagem ${ }^{29}$. Aquellos archivos en que el ingeniero brasileño Santos Dumont exponía en 1901 su proyecto de dirigible a C. S. Rolls. A partir de la digitalización de esos fragmentos pre-cinematograficos, se reformula la esencia del aparato, el mutoscopio, analizando su forma de descomponer y reconstituir el movimiento a través de tarjetas con imágenes fotográficas. La digitalización de esas imágenes no se limita a archivar y recuperarlas sino que las reinterpreta, compilándolas a nivel informático. Es en este procesamiento numérico que Adriano, propone su teorema sobre esas imágenes y el valor exegético de aquella máquina precinemática documentando hechos históricos. El resultado de este cortometraje experimental fue trasladado, digital to film, a un negativo $35 \mathrm{~mm}$. para un proceso sintomático en cuanto a las combinatorias de soportes distanciados por un siglo de cine, del mutoscopio al video digital y de la imagen numérica al $35 \mathrm{~mm}$. Por su parte, en ¿Santos Dumont pre-cineasta ${ }^{30}$ ?, Adriano imbrica varias vertientes del ensayo documental, uno de cuyos temas es el seguimiento de la investigación, y el desarrollo de su tesis, donde relaciona las invenciones de Santos Dumont como búsquedas asociadas a los albores del cine, vinculadas a su vez al desarrollo arquitectónico. Las estructuras urbanas de hierro de fines del siglo XIX, los inicios de la aeronavegación, se relacionan como dispositivos de comunicación vinculados a la revolución industrial y a las máquinas resultantes provenientes de textos científicos. Ante la imposibilidad de filmar, el video digital permite la captura de estos trayectos de pensamiento en que los archivos encontrados conviven con las máquinas que los produjeron hace más de cien años. Es a través de la imagen informática que Adriano escribe las maneras de documentar desde la contemporaneidad una arqueología de la imagen en movimiento electro/mecánica/fotoquímica.

Adriano, Bambozzi, Cantoni, Kac, Kogut y Kutschat son figuras de referencia para un amplio elenco que desde Brasil vienen ofreciendo un sólido discurso que se afirma en prácticas artísticas que se ubican incómodamente en el ámbito del arte contemporáneo y reflexiona sobre los usos de las artes visuales 
tecnológicas. Un relato que pone en movimiento aquellas preocupaciones visionarias de autores, artistas, cineastas experimentales y video cradores del Siglo XX que parecen haber quedado en el olvido y que siguen siendo una referencia frente al anquilosamiento de las escenas de instrucción, al consenso del espectáculo de los medios masivos y a los discutibles criterios curatoriales de las instituciones que se dedican a la entelequia del arte comtemporáneo en el Brasil. La propuesta de esta presentación, focalizada en este riesgoso panorama sobre autores brasileños realizado por un extranjero, propone un intercambio de ideas que hacen a una historia de prácticas artísticas transversales con los medios donde la formación sigue jugando un rol central la cual sigue buscando un lugar apropiado desde el campo de la praxis y los estudios audiovisuales.

\section{Referencias}

ALONSO, Rodrigo (comp.). Con/textos. Una antología críti$c a$. Buenos Aires: Editorial Simurg/Cátedra La Ferla-UBA., Universidad de Buenos Aires, 2002.

BELLOUR, Raymond. Entre Imágenes. Foto, Cine, Video. Buenos Aires: Ed. Colihue, 2009.

BARTLETT, Mark. Expanded Cinema: Art, Performance, Film. Londres: Tate Publishing, 2011.

BELLOUR, Raymond, La Querelle des Dispositifs, POL, París, 2012.

BÜRCH, Noel. Praxis del Cine. Madrid: Fundamentos, 1976.

Expanded Cinema: Art, Performance, Film, Tate Publishing, Londres, 2011.

FRODON, Jean-Michel, Cinéma et musées, Cahiers du cinéma, Nro. 611, abril de 2006, pp. 8-10.

CANCLINI, Néstor García. Culturas híbridas. Estrategias para entrar y salir de la modernidad. Buenos Aires: Paidós, 2005.

MELLO, Saulo Pereira de (Ed.). Mário Peixoto. Escritos sobre cinema. Rio de Janeiro: Aeroplano/ Arquivo Mário Peixoto, 2000.

PARENTE, André, Cinema em Trânsito. Cinema, arte contemporânea e novas midias", Beco do Azougue, Rio de Janeiro, 2011.

PEIXOTO, Mário. Um filme da América do Sul. Revista Arquitetura, n. 30, ago. 1965. In MELLO, Saulo Pereira de (ed.). Mário Peixoto. Escritos sobre cinema. Rio de Janeiro: Aeroplano/Arquivo Mário Peixoto, 2000.

POLAN, Dana: Scenes of Instruction: The Beginnings of the 
US Study of Film, University of California Press, Berkeley y London, 2007.

RODRIGUES, Luciana. O ensino do cinema. Tesis de maestría dirigida por María Dora Mourao, USP, 2008.

VASULKA, Woody y Weibel, Peter (Eds.): Buffalo Heads. Media Study, Media Practice, Media Pioneers, 1973-1990, MIT Press/ZKM, Cambridge/Karlsruhe, 2008.

WASSON, Haidee: Museum Movies. The Museum of Modern Art and the Birth of Art Cinema, University of California Press, Los Angeles, 2005.

YOUNGBLOOD, Gene. Expanded Cinema. New York: P. Dutton \& Co., Inc., 1970/ Cine Expandido. Caseros, Buenos Aires: Universidad Nacional Tres de Febrero, 2012.

\section{NOTAS}

1. Para el contexto de Brasil, son referencia los estudios de Lucia Santaella y Arlindo Machado, y una génesis en este campo, iniciada por Vilém Flusser.

2. "Es increíble cuando pienso qué pesimista era nuestra previsión en 1982. Es increíble como se ha mantenido de bien el cine. No sólo superó nuestras expectativas de ese momento, sino también la de los años noventa y en el siglo XXI, salió solo del pozo en el que se encontraba. El cine está más vivo que nunca Wim Wenders en Spolidoro, Gustavo: Back to Room 666, Brasil, 2008.

3. "Híbrido es modelo y predisposición para llegar a ser y significar salto, mutación. Una interpretación por hibridación se conduciría por los dispositivos de cruzamiento, en un sentido de interponerse, de atravesar; y de mutación, en un sentido de conversión sustancial o de naturaleza, de sustitución de una cosa o un estado" (MERCADER, ANTONI in ALONSO, RODRIGO, 2002).

4. Ver Canclini (2005).

5. Bellour (2012).

6. Bürch (1976).

7. Griffith, David W: Nacimiento de una Nación, Estados Unidos, 1915.

8. EISENSTEIN, Sergei. “The tatler magazine”, Londres, out. 1931. Na verdade, o texto é um apócrifo atribuído a Eisenstein e escrito pelo próprio Mário Peixoto, mais tarde publicado em MELLO (2000).

9. Griffith, David W.: Birth of a Nation, USA, 1915.

10. Polan (2007).

11. Recordemos que la primera escuela de cine en en el Brasil y América Latina surge poco después, Azzurri en San Pablo que se funda en 1920 Ver Rodrígues (2008).

12. Wasson (2005).

13. Vasulka y Weibel (20o8).

14. http://medialab.ufg.br/site/ 
15. Ver "Socialimagestics and the Visual Acupuntura of Stan Vanderbeek's Expanded Cinema”, em Bartlett (2011).

16. "Cinema de vanguardia, cinema experimental e cinema do dispositivo", em Parente (2012).

17. "Porque se trata efectivamente de un acontecimiento, con el carácter a la vez inédito y decisivo que esa palabra supone. Desde hace un siglo el cine flirtea con los museos, y al cine le gusta también filmar los museos por mil razones." (FRODON, 2006, p. 8-10)

18. http://www.oifuturo.org.br/evento/exporgodard-viagens-em-utopia/

19. Ver Reportage amateur (maquette expo), Jean-Luc Godard/Anne-Marie Miéville, $47^{\prime}$, Francia/Suiza, 2006.

20. Parente (2011).

21. Kogut, Sandra: Las videocabinas son cajas negras, Brasil, 1990.

22. Kogut, Sandra: Parabolic People, Brasil/Francia, 3' x 11, 1991.

23. Kogut, Sandra: Lá e Cá, Brasil/Francia,1995.

24. Kogut, Sandra: Mutum, Brasil/Francia, 2007.

25. http://www.ekac.org/figs.html

26. Cantoni, Rejane/Kutschat, Daniela: Op_era, 2001/2008, ver www.op-era. com.

27. OP_ERA: uma jornada a traves de dimensões paralelas e experimentos multisensoriais, DVD, 6o', Itaú Cultural, 2003.

28. No es casualidad que la investigación de Adriano haya sido realizada en el marco de un doctorado dirigido por Ismail Xavier, uno de los mayores referentes de la teoría cinematográfica en el continente. Adriano logra un diálogo inédito sobre el cine en base a una reflexión que se articula a través de la manipulación de imágenes en el ordenador.

29. Adriano, Carlos: SANTOSCÓPIO = DUMONTAGEM, DV CAM $/ 35 \mathrm{~mm}$, Dolby digital 5.1, 14'31' , Brasil, 2007/2009. (não aparece nas referências)

3o. Adriano, Carlos: SANTOS DUMONT PRÉ-CINEASTA?, HDV, estéreo, $63^{\prime} 5^{\prime \prime} 7$ cuadros, Brasil, 2007/2010.

Recebido em: 30/09/2013

Aceito em: 30/10/2013 


\section{JORGE LA FERLA \\ jorgelaferla@gmail.com \\ Licenciado en la Universidad de París VIII, es Master in Arts por la Universidad de Pittsburgh donde también es egresado del Programa para Graduados del Centro de Estudios Latinoamericanos. Es profe- sor e investigador en Medios Audiovisuales, con realizaciones en video y multimedia. Ha sido fundador y director de las 10 ediciones de las muestras EuroAmericanas de Cine, Video y Arte Digital organizadas por la Universidad de Buenos Aires y la Embajada de Francia entre 1995 y 2002. Asimismo es Profesor Titular de cátedra en la Universidad de Buenos Aires y en la Universidad del Cine y profesor invitado de la Universidad de los Andes en Bogotá. Es curador, docente, conferencista y artista en eventos audiovisuales y actividades académicas en América, Europa y Medio Oriente. Ha compilado más de treinta publicaciones sobre Artes y Medios Audiovisuales en Argentina, Brasil y Colombia. Su último libro es Cine (y) Digital, ed. Manantial, Buenos Aires, 2009.}

